\title{
ハイブリッド型微細加工技術を用いた 金ナノ粒子の単電子トンネル効果の観測
}

根岸 良太*1 ·田中 啓文*2

\section{Observation of Single Electron Effect of the Au Nanoparticles using Hybrid Type Nanofabrication Technique}

\author{
Ryota NEGISHI*1 and Hirofumi TANAKA*2 \\ ${ }^{*}$ Semiconductors Laboratory, The Institute of Physical and Chemical Research (RIKEN), \\ 2-1, Hirosawa, Wako, Saitama 351-0198, Japan \\ *2Research Center for Molecular-Scale Nanoscience, Institute for Molecular Science, \\ 5-1 Higashiyama, Myodaiji, Okazaki, Aichi 444-8787, Japan \\ (Present address: Department of Chemistry, School of Science Osaka University, Machikaneyama Toyonaka 560-0043, Japan) \\ (Received October 12, 2007, Accepted January 12, 2008)

\begin{abstract}
We would like to share our recent results from a research on the single electron tunneling effect in a double-barrier tunneling junction (DBTJ) structure. Single Au nanoparticles were trapped in a nanogap electrodes, whose gap size was precisely controlled using a combination of electron beam lithography and molecular ruler technique. Here, we introduce how the novel combination technique was utilized to obtain the nanogap electrode. We also introduce the size effect of Au particles on the single electron tunneling behavior as a Coulomb island. Finally, we introduce the relation between the geometrical and electrical properties of the DBTJ.
\end{abstract}

\section{1. はじめに}

シリコンを基盤とした半導体デバイスの集積化は，ムーア の法則にて提言されているように, その集積度は 2 年毎に 約 2 倍の増加を実現しており, 現在, 素子のサイズはナノ 領域にまで迫っている，そのため，これまでの動作原理とは まったく異なる量子力学的効果を積極的に取り入れた新概念 によるナノデバイスの開発が求められている.

ナノスケールオーダーの幅を持つナノギャップ電極間に量 子ドットを配置させた微小トンネル二重接合素子では, 一個 の電子がトンネル障壁を通り抜け中央の量子ドット内に注入 されるたびに, トンネル障壁内に強い斥力電界形成され, 静 電エネルギーの変化が生じる，そのため, 外部からのある一 定以上のエネルギーを加えない限り, 次の電子によるトンネ リング伝導が抑制されるクーロンブロッケード現象が出現す る.この現象は, 量子ドット内の電子を一つずつ制御するこ とによる一電子輸送を利用した単電子トランジスタの創出を 可能とし, 量子力学的効果を積極的に利用した新しいナノデ バイスの動作原理として高い関心を集めている．このような 一電子制御のためには, 量子ドットのサイズや形状のみなら ず，それをリード線につなげる接合部分の構造と，その素子 構造から得られる電気伝導特性の相関を包括的に理解するこ とが重要となっている.これらの問題を解決するために, 我 々はこれまでにナノギャップ電極を用いた金ナノ粒子の単電 子トンネリング効果の測定を行ってきた. 本解説では, (1)量

*1 理化学研究所・石橋極微デバイス工学研究室 (下351-0198 埼 玉県和光市広沢 2-1 中央研究所研究交流棟 4F)

*2 自然科学研究機構 - 分子科学研究所 - 分子スケールナノサイエ ンスセンター（テ444-8787 愛知県岡崎市明大寺町字東山 5-1) (現: 大阪大学大学院理学研究科化学専攻 物性有機化学研 究室 干560-0043 大阪府豊中市待兼山町 1-1)
子ドットのサイズと電気伝導特性の関係, (2)接合構造の対称 性と電気伝導特性の関係に注目した最近の研究成果を中心に 紹介する。

\section{2. ハイブリッド型微細加工技術の応用}

ナノスケールオーダーの幅を持つナノギャップ電極は, ナ ノ微粒子や単一分子など次世代の電子デバィスのビルディン グブロックと成りうるナノ構造体の電子物性を解明するのに 有効であり, 近年ブレイクジャンクション法1)や斜め蒸着 法2,3), エレクトロンマイグレーション法4), 収束イオンビー ムによる加工法5)など様々なナノギャップ電極の作製法が考 案され，微粒子や単分子に抢けるクーロンブロッケード6)や 近藤効果 7,8$)$, 負の微分抵抗 ${ }^{1)}$, スイッチング現象 ${ }^{9,10)}$ など興 味深い物理現象が報告されている.

これまで, 分子の自己組織化膜をレジストとして用いるユ ニークな微細加工手法である分子定規法11-13) とUV 描画法 を併用したハイブリッド型微細加工技術 ${ }^{14)}$ が Anderson らに よって開発され，ギャップ電極作製手法の一つとして高い関 心を集めている. 我々はこの分子定規法を電子線描画法に応 用し発展させることで, 従来の分子定規法では困難であった ナノギャップの位置制御を, 極めて高い精度で実現すること に成功した ${ }^{15)}$.これまでの研究で開発してきたナノギャッ プ電極の作製手順を Fig. 1 に示す. まず始めに, 電子線描 画で金電極パターン（第一電極）を作製し（Fig. 1(a)），次 にサンプルを16-mercaptohexadecanoic acid（MHDA）及 び銅イオンのそれぞれの溶液に交互に浸漬する。この時, MHDAの末端部のチオール基は, 金電極表面上に自己組織 化分子膜を形成し, 次に銅イオンは MHDAのもう一端の $\mathrm{COOH}$ 基に選択的に吸着するので，金電極表面上には MHDA · 銅イオン $\cdot$ MHDA · 銅イオン …加らる多層 膜（以下分子定規）が積層されていく（Fig. 1(b)).この多 
層膜の積層構造は Evansによって詳細に解析されてい る16). 次に 2 度目の電子線描画により，第二電極を作製し た後 (Fig. 1(c)), 分子定規を除去することにより, その領 域に分子定規の膜厚に一致したナノギャップが選択的に形成 される (Fig. 1(d)). 分子定規の膜厚は一層ずつ制御するこ

(a)

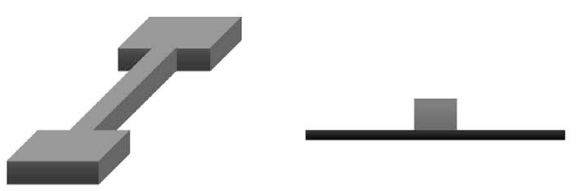

(b)
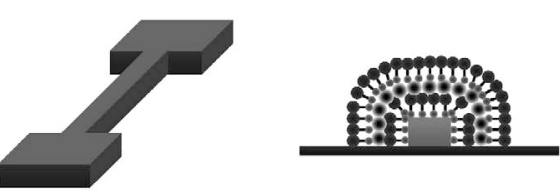

(c)

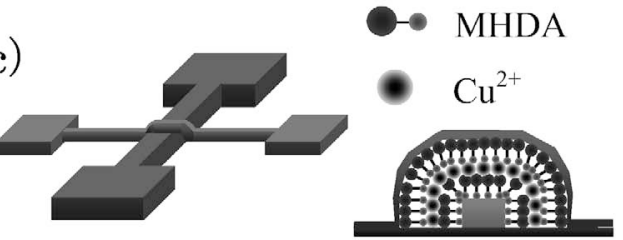

(d)



Fig. 1 Schematic drawing of the fabrication process. (a) Electron beam lithography (EBL) is used to make the first metal electrode and the metal layer is deposited by sputtering. (b) Multilayer films (molecular ruler) composed of the MHDA and $\mathrm{Cu}^{2+}$ are constructed layer by layer on surface of the first metal. (c) EBL is used to make the second metal electrode. (d) Molecular ruler is chemically removed by ACT935J.
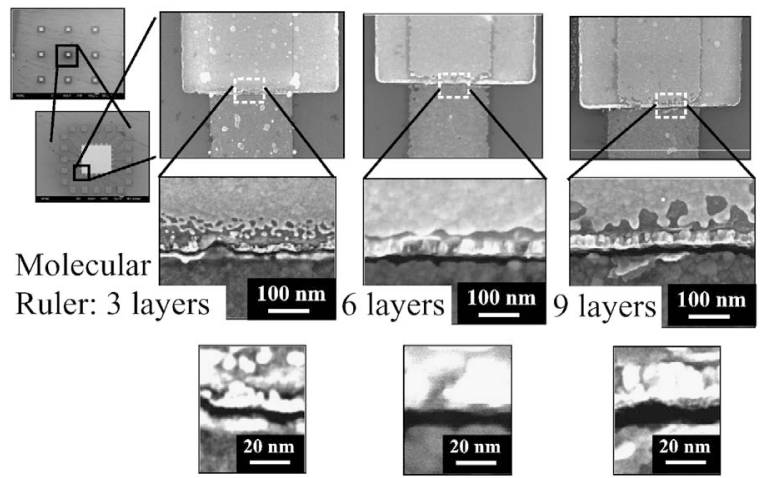

9 layers $\mathbf{1 0 0} \mathbf{n m}$

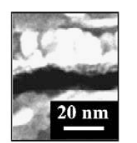

Fig. 2 SEM image of the nanogap electrodes fabricated by the hybrid technique of EBL and molecular ruler method. First and second metal electrodes are composed of $\mathrm{Au}(80$ $\mathrm{nm}) / \mathrm{Cr}(10 \mathrm{~nm})$ and $\mathrm{Au}(20 \mathrm{~nm}) / \mathrm{Cr}(10 \mathrm{~nm})$, respectively. According to increase of the film thickness of the molecular rule, the width of the gap increases.
とが可能なので, 一分子長 $(\sim 2 \mathrm{~nm})$ の精度で目的のギャ ップ幅を有する電極を作製することができる.ささに電子線 描画法の併用により，ギャップの位置や形状を精密に制御す ることも可能となった.

本手法によって作製されたナノギャップ電極の走查型電子 顕微鏡（SEM）像を Fig. 2 に示す。それぞれの SEM 像か ら見積もられるギャップ幅は，それぞれ約 $6,13,19 \mathrm{~nm}$ で あり, ギャップ作製に用いられた分子定規 $3,6,9$ 層分の膜 厚と良い一致を示す．このように，本手法では一分子層の長 さ（２ｎm）でギャップ幅を制御することが可能であり， 精密に構造制御されたナノギャップ電極の作製が可能である.

\section{3. 量子ドットのサイズと電気伝導特性の関係}

クーロンブロッケード現象を観察するためには，微小トン ネル二重接合間に蓄えられる静電エネルギーが電子の熱励起 エネルギーよりも十分に高くなる必要がある. そのため, 接 合間の静電エネルギーを決める主要な要素である量子ドット のサイズと現象が起こる温度の関係を詳細に理解すること が, 室温動作可能な単電子トランジスタ実現への鍵となる. そこで我々は，ドデカンチオールを被覆したサイズの異なる 二種類の金ナノ粒子（直径約 $5 \mathrm{~nm}, 1.6 \mathrm{~nm}$ ）をクーロン島 として，ナノギャップ電極を用いた単電子トンネリングの測 定を行った ${ }^{17)}$.

ここで，クーロンブロッケード現象を観察するためのもう 一つの重要な点として, 量子摇らぎにより現象がぼやけてし まわないよう接合抵抗值が量子抵抗值よりも大きいこと，一 方で検出が困難になるほど接合抵抗值が大きすぎないことが 挙げられる.そのため，ナノギャップ電極のギャップ幅は， 可能な限り量子抵抗となるリガンド（保護分子：本研究では ドデカンチオールを使用）を含んだ微粒子のサイズと一致す るように設計する必要がある，前章で紹介したように，本手 法ではレジストとして用いる分子定規を一分子長オーダーで 制御することが可能なので, 我々はナノギャップ電極のギャ ップ幅を，約 $2 \mathrm{~nm}$ のオーダーで制御することが出来る.リ ガンドを含んだ金ナノ粒子の直径は各々約 $8 \mathrm{~nm}, 4.6 \mathrm{~nm}$ と なるため,レジストとして用いる分子定規 5 層, 3 層を用い てサイズの異なる二種類のギャップ電極を作製した。

Fig. 3 (a), 3(b)に, 測定温度 $10 \mathrm{~K}$, 直径約 5, $1.6 \mathrm{~nm}$ の金 ナノ粒子から得られた電流-電圧曲線（丸）とその微分コン ダクタンス (実線) を示す。それぞれの曲線において, 印加 電圧 $0 \mathrm{~V}$ 付近に電子のトンネリングに対する強い抑制領域 （クーロンギャップ）が観察されている。これは金ナノ粒子

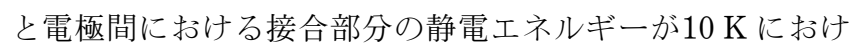
る電子の熱励起エネルギー $\left(k_{\mathrm{B}} \mathrm{T} \sim 0.86 \mathrm{meV}\right)$ よりも十分に 大きいことを示しており，明瞭なクーロンブロッケードが観 察されたことを意味している。一方, 室温で測定された電 流一電圧曲線を Fig. 3(a), 3(b)の左上挿入図 (実線)に示す. 直径約 $5 \mathrm{~nm}$ の金ナノ粒子から得られた電流一電圧曲線で は，クーロンギャップは観察されず，電流值は電圧に対して 直線的な増加を示している，一方，小さい金ナノ粒子から得 られた電流一電圧曲線に打いては，領域は減少したものの クーロンギャップが観察されている．このことは，直径 1.6 

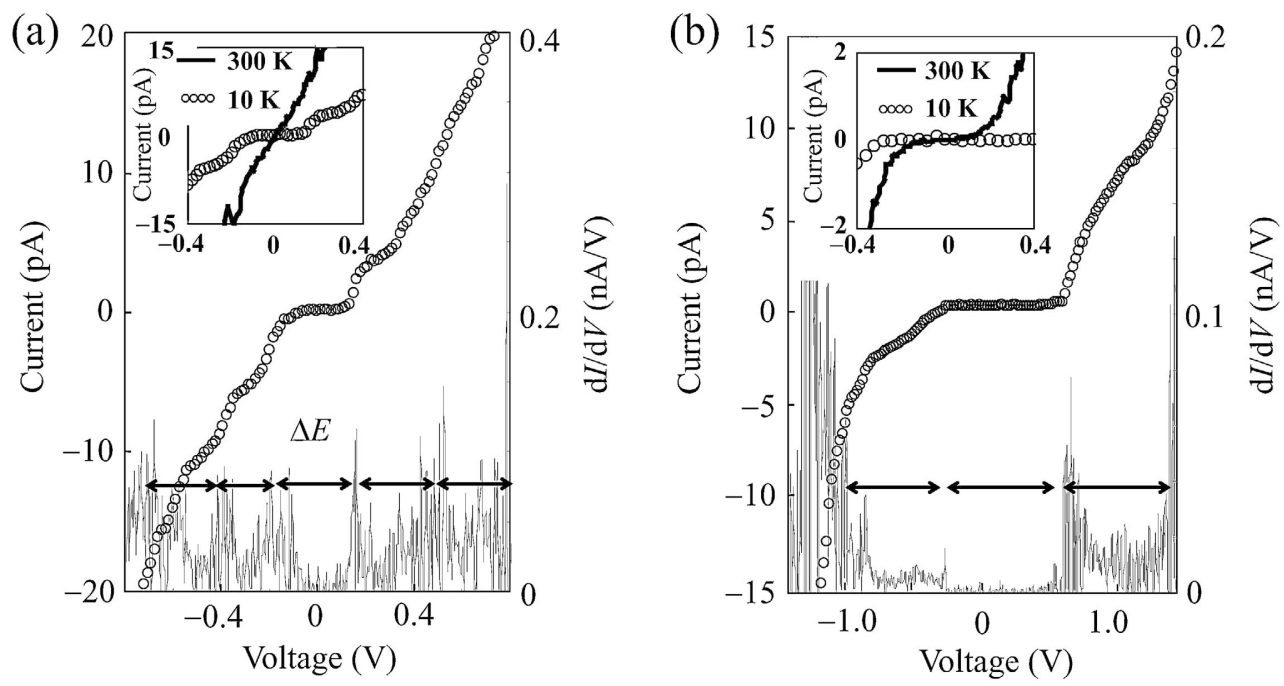

Fig. 3 Current-voltage curves (open circles) and their differential conductance spectra (solid line) obtained from the Au nanoparticle whose size is (a) $5 \mathrm{~nm}$, (b) $1.6 \mathrm{~nm}$, respectively. According to decrease of the particle size, the region of the Coulomb gap $(\Delta \mathrm{E})$ caused by the suppression of the tunneling electron around zero bias voltage increase. Enlarged current-voltage curves measured at $10 \mathrm{~K}$ and room temperature around zero bias voltage are shown in the inset.

$\mathrm{nm}$ 程度の金ナノ粒子をクーロン島として用い，接合部分を 精密に制御することで，室温で動作する単電子デバイスの作 製が可能なことを示唆している.

\section{4. 接合構造の対称性と電気伝導特性の関係}

単電子トンネリングの電気伝導特性は, Fig. 4 に示す微 小トンネル二重接合モデルに基づくクーロンオーソドックス 理論 ${ }^{18-20)}$ によって良く記述されている。例えば，微小トン ネル二重接合における接合抵抗值 $\left(\mathrm{R}_{1}, \mathrm{R}_{2}\right)$ とキャパシタン 又 $\left(\mathrm{C}_{1}, \mathrm{C}_{2}\right)$ の積である時定数が両者でほほ等しい場合 $\left(\mathrm{C}_{1} \mathrm{R}_{1} \cong \mathrm{C}_{2} \mathrm{R}_{2}\right)$ には，接合を流れる電流值は印加電圧 $0 \mathrm{~V}$ 近 傍で見られるクーロンギャップ領域を越えて，電圧に対して 単調に増加する。一方，時定数が両者で大きく異なる場合 $\left(\mathrm{C}_{1} \mathrm{R}_{1} \ll \mathrm{C}_{2} \mathrm{R}_{2}\right.$ 或いは $\left.\mathrm{C}_{1} \mathrm{R}_{1} \gg \mathrm{C}_{2} \mathrm{R}_{2}\right)$ には，電荷の流れが時定 数の大きな接合部分で律速されることから, 電流-電圧曲線 は階段状のスペクトル，いわゆるクーロンステアケースを示 すことが理論的に予測されている。このようなスペクトル は, ナノギャップ電極 ${ }^{21,22}$ や走查型トンネル顕微鏡法/分光 法 (STM/STS $)^{23-25)}$ により既に実験的に観察されている. しかしながら，ナノギャップ電極では電極間に多数の微粒子 が存在するため接合構造が不明瞭であり，一方 STM/STS では接合構造自体を直接観察することができないため，これ まで理論的に予測される電流一電圧特性と接合構造を直接結 びつける明確な証拠はなく，実験結果に基づく間接的な推測 に留まっていた，そこで我々は，精密に構造制御されたナノ ギャップ電極間に一微粒子の久を配置させることにより，微 粒子-電極間に抢淁合部分の構造を評価し，そこから得 られる電気伝導特性を調べることで，両者を結ぶ直接的証拠 を見出したので紹介する26).

接合構造に特徴を持たせるため測定に用いた電極のギャッ プ幅は，ドデカンチオールを含む金ナノ粒子のサイズと同じ

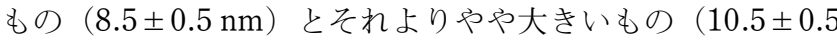
$\mathrm{nm}$ ）の二種類を作製した。ささに，ギャップ間に一微粒子

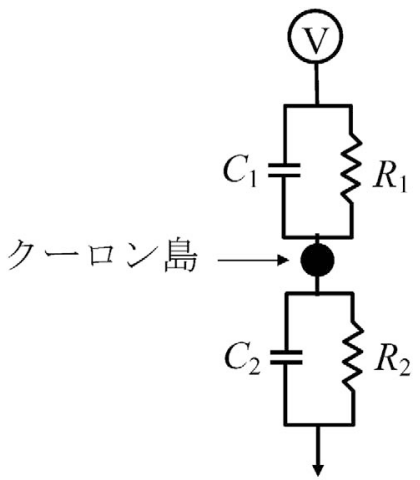

Fig. 4 Electrical circuit diagram of the double-barrier tunneling junction model.
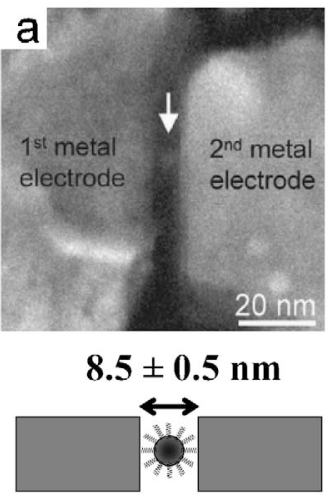

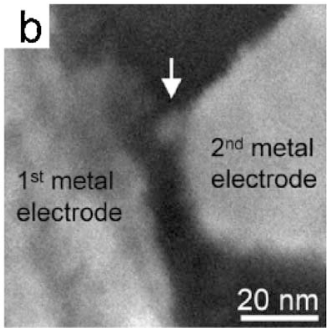

$10.5 \pm 0.5 \mathrm{~nm}$

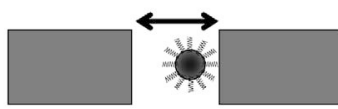

Fig. 5 SEM image of the nanogap electrodes after the dispersion of the dodecanethiol-coated Au nanoparticles. The width of the gap is (a) $8.5 \pm 0.5 \mathrm{~nm}$, (b) $10.5 \pm 0.5 \mathrm{~nm}$, respectively. The nanogaps geometrically form a symmetric and an asymmetric double-barrier tunneling junction. Illustrations of the gap regions are also shown in the lower part.

の反を配置させるように，分散する金ナノ粒子の濃度を調整 した. 作製された接合構造の SEM 像を, Fig. $5(\mathbf{a}), \mathbf{5}(\mathbf{b})$ に 示す.ギャップ幅を変化させることにより，金ナノ粒子がギ 

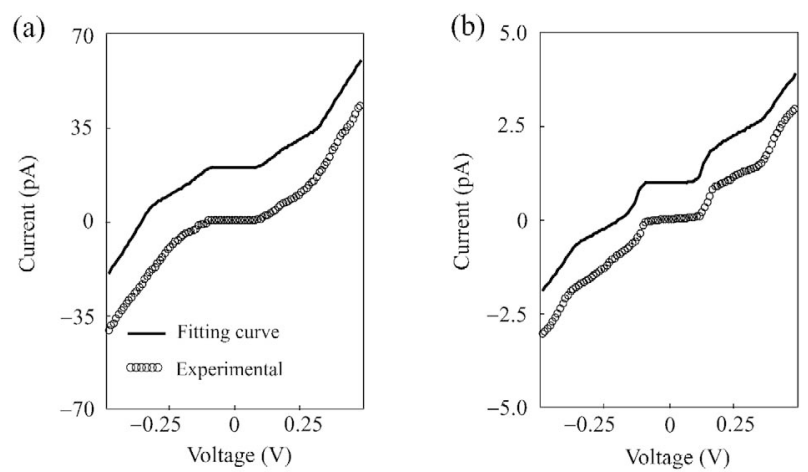

Fig. 6 Current-voltage curves measured at $10 \mathrm{~K}$ (open circles) obtained from symmetric and asymmetric junctions shown in Fig. 5 (a) and 5(b), respectively. The fitting curves (solid lines) are obtained using the Coulomb orthodox theory. The junction parameters are (a) $\mathrm{C}_{1}=0.72 \mathrm{aF}, \mathrm{C}_{2}=0.76 \mathrm{aF}$, $\mathrm{R}_{1}=3.9 \mathrm{G} \Omega, \mathrm{R}_{2}=3.7 \mathrm{G} \Omega, \mathrm{Q}$ (offset charge) $=0.001 \mathrm{e}, \mathrm{C}_{1} \mathrm{R}_{1} / \mathrm{C}_{2}$ $\mathrm{R}_{2} \approx 1.0$, (b) $\mathrm{C}_{1}=0.35 \mathrm{aF}, \mathrm{C}_{2}=0.65 \mathrm{aF}, \mathrm{R}_{1}=127 \mathrm{G} \Omega, \mathrm{R}_{2}=3.1$ $\mathrm{G} \Omega, \mathrm{Q}=-0.01 \mathrm{e}, \mathrm{C}_{1} \mathrm{R}_{1} / \mathrm{C}_{2} \mathrm{R}_{2} \approx 22.1$.

ヤップ中央部・電極片側にそれぞれ位置した対称・非対称接 合が形成されているのが分かる．このような電極から得られ た電流-電圧曲線の実験值（点線）とクーロンオーソドック 久理論18-20)に基づくフィッティング曲線（実線）を Fig. $\mathbf{6}(\mathbf{a}), \mathbf{6}(\mathbf{b})$ に示す.フィッティング曲線は最小二乗法により 得られた。対称接合から得られた電流-電圧曲線では, 印加 電圧 $0 \mathrm{~V}$ 近傍で見られるクーロンギャップ領域の電圧閾値 を越えた後, 電流值の単調な増加が見られる。一方, 非対称 接合ではクーロンステアケースが観察されている，さらに， フィッティングパラメータである二つの接合の時定数 $\left(\mathrm{C}_{1} \mathrm{R}_{1}, \mathrm{C}_{2} \mathrm{R}_{2}\right)$ は, Fig. 6(a)の接合構造に対してはほぼ等し いのに対して, Fig. 6(b) の接合構造に対しては時定数比 $\left(\mathrm{C}_{1} \mathrm{R}_{1} / \mathrm{C}_{2} \mathrm{R}_{2}\right)$ が約 22 と電気的にも非対称性を示し, 観察さ れた構造的特徵を支持しているのが分かる.

我々は, フィッティング曲線から得られた接合パラメータ が妥当な值であるかを検証するために, 観察された構造的特 徵に基づいて鏡像法27)によるキャパシタンスの計算を行っ た ${ }^{26)}$ ．ここで，金ナノ粒子のサイズは $5 \mathrm{~nm}$ ，金ナノ粒子の リガンドであるドデカンチオールの長さとその誘電率を各々 $1.5 \mathrm{~nm}, 3.028)$ とした。 その結果, 非対称接合に抢ける微 小トンネル二重接合のキャパシタンス $\mathrm{C}_{1}, \mathrm{C}_{2}$ は, それぞれ $0.65 \pm 0.05 \mathrm{aF}, 0.35 \pm 0.05 \mathrm{aF}$ と求められ, フィッティング パラメータと良い一致を示した。このように, 精密に構造制 御した微小トンネル二重接合間に一微粒子の及を配置させ, そこから得られる電流一電圧曲線を評価することにより, 接 合の構造的特徵と電気伝導特性の両者を直接結びつけること に成功した26).

\section{5. 終わりに}

ナノギャップ電極を用いた単電子トンネリングに関する最 近の研究成果を紹介した. 直径 $1.6 \mathrm{~nm}$ 程度の金ナノ粒子を クーロン島として用い，接合部分を精密に作製することで， 室温に扔いても明膫なクーロンブロッケードの観察に成功し た。これは, 室温動作可能な単電子デバイス実現に向けて大
きな期待を抱かせてくれる結果である。課題は, 第三電極 (ゲート電極) による単電子輸送の制御である. クーロン島 である量子ドットはサイズが微小なため, 自己キャパシタン スが小さくゲート電極による制御のためには高い電圧值が必 要となり, リーク電流等の問題が発生することが予測され る. そこで,ゲート絶緑膜にはリーク電流を抑えつつキャパ シタンスを大きくするために, $\mathrm{HfO}_{2} や \mathrm{Al}_{2} \mathrm{O}_{3}$ などの高誘電 率絶縁素材を採用することが鍵になると思われる．

一方, 精密に構造制御されたナノ接合間に強相関材料から なる微粒子や単分子を架橋させることで, ナノ接合素子の機 能や多様性は飛躍的に向上することが容易に想像つく，例え ば，半導体量子ドットや単分子を素子のコアとして用いれ ば, 離散化した量子準位や分子軌道を量子ビットとしたスピ ンデバイス素子の創出が期待される. 現在我々は, このよう な電子の電荷としての性質だけではなく, 電子スピンを新た な自由度として量子力学的に制御できるナノ接合素子の創出 に向けて研究を進めているところであり, 今後の展開が注目 される.

\section{謝辞}

本研究の一部は, 科学技術振興機構・ナノ量子導体アレー プロジェクトの研究として行われたものです. 本研究を遂行 するに当たり, 有用な議論をしていただきました分子科学研 究所・分子スケールナノサイエンスセンターの小川环治教授 (現大阪大学), 小沢寛晃博士 (現名古屋大学) に感謝申し上 げます。

\section{〔文献〕}

1) M. A. Reed, C. Zhou, C. J. Muller, T. P. Burgin and J. M. Tour: Science, 278 (1997) 252.

2) G. Philipp, T. Weimann, P. Hinze, M. Burghard and J. Weis: Microelectron. Eng., 46 (1999) 157.

3) Y. Naitoh, K. Tsukagoshi, K. Murata and W. Mizutani: e-J. Surf. Sci. Nanotech., 1 (2003) 41.

4) H. Park, A. K. L. Lim, A. P. Alivisatous, J. Park and P. L. McEuen: Appl. Phys. Lett., 75 (1999) 301.

5) M. Nakayama, F. Wakaya, J. Yanagisawa and K. Gamo: J. Vac. Sci. Technol., B 16 (1998) 2511.

6) H. Park, J. Park, A. K. L. Lim, E. H. Anderson, A. P. Alivisatos and P. L. McEuen: Nature, 407 (2000) 57.

7) J. Park, A. N. Pasupathy, J. I. Goldsmith, C. Chang, Y. Yaish, J. R. Petta, M. Rinkoski, J. P. Sethna, H. D. Abruna, P. L. McEuen and D. C. Raplh: Nature, 417 (2002) 722.

8) W. Liang, M. P. Shores, M. Bockrath, J. R. Long and H. Park: Nature, 417 (2002) 725.

9) J. Chen, M. A. Reed, A. M. Rawlett and J. M. Tour: Science, 286 (1999) 1550.

10) M. A. Reed, J. Chen, A. M. Rawlett, D. W. Price and J. M. Tour: Appl. Phys. Lett., 78 (2001) 3735.

11) A. Hatzor and P. S. Weiss: Science, 291 (2001) 1019.

12) M. E. Anderson, R. K. Smith, Z. J. Donhauser, A. Hatzor, P. A. Lewis, L. P. Tan, M. W. Horn and P. S. Weiss: J. Vac. Sci. Technol., B 20 (2002) 2739.

13) M. E. Anderson, L. P. Tan, H. Tanaka, M. Mihok, H. Lee, M. W. Horn and P. S. Weiss: J. Vac. Sci. Technol., B 21 (2003) 3116.

14) M. E. Anderson, M. Mihok, H. Tanaka, L.-P. Tan, M. W. Horn, G. S. McCarty and P. S. Weiss: Adv. Mater., 18 (2006) 1020. 
15) R, Negishi, T. Hasegawa, K. Terabe, M. Aono, T. Ebihara, H. Tanaka and T. Ogawa: Appl. Phys. Lett., 88 (2006) 223111.

16) D. Evans, A. Ulman, Kim E. Gopper-Berarducci, Louis J. Gerenser, J. Am. Chem. Soc. 113 (1991) 5866.

17) R. Negishi, T. Hasegawa, H. Tanaka, K. Terabe, H. Ozawa, T. Ogawa and M. Aono: Surf. Sci., 601 (2007) 3907.

18) D. V. Averin and K. K. Likharev, Mesoscopic Phenomena in Solids, edited by B. L. Altshuler, P. A. Lee and R. A. Webb (North-Holland, New York, 1991), Chap. 6.

19) M. Amman, R. Wilkins, E. Ben-Jacob, P. D. Maker and R. C. Jaklevic, Phys. Rev., B 43 (1991) 1146.

20) A. E. Hanna and M. Tinkham, Phys. Rev., B 44 (1991) 5919.

21) D. L. Klein, R. Roth, A. K. L. Lim, A. P. Alivisatos and P. L. McEuen: Nature, 389 (1997) 699.
22) K. I. Bolotin, F. Kuemmeth, A. N. Pasupathy and D. C. Ralph: Appl. Phys. Lett., 84 (2004) 3154.

23) M. Dorogi, J. Gomez, R. Osifchin, R. P. Andres and R. Reifenberger: Phys. Rev., B 52 (1995) 9071.

24) K.-H. Park, J. S. Ha, W. S. Yun, M. Shin, K.-W. Park and ELHang Lee: Appl. Phys. Lett., 71 (1997) 1469.

25) H. Osman, J. Schmidt, K. Svensson, R. E. Palme, Y. Shigeta and J. P. Wilcoxon: Chem. Phys. Lett., 330 (2000) 1.

26) R. Negishi, T. Hasegawa, H. Tanaka, K. Terabe, T. Ogawa, H. Ozawa and M. Aono: Appl. Phys. Lett., 90 (2007) 223112.

27) C. Gao, F. Duewer and X. D. Xiang: Appl. Phys. Lett., 75 (1999) 3005.

28) M. A. Rampi, O. J. A. Schueller and G. M. Whitesides: Appl. Phys. Lett., 72 (1998) 1781. 